\title{
A Pilot Study: Ayurvedic Approach on Memory Stimulation in Guadeloupe
}

\author{
Yenkamala Mina Ananda \\ Ayurvedic Institute of Guadeloupe, Guadeloupe, French West Indies
}

\begin{abstract}
Background: The need to prevent from Alzheimer disease led us to offer sessions of cognitive stimulation. Aim: to evaluate effectiveness of cognitive stimulation and the relevance of ayurvedic categories in a nondemented population. Methods: We studied the ayurvedic categories, the perception of overall health, the complaint and the evolution of associative memory in 28 healthy elderly at T1 and T2 (three months after) including 12 healthy controls who aren't stimulated, this in a self-assessment questionnaires including Prakriti and complaint of memory, several scales of perceived health (cognitive, physical, mental, and well-being/quality of life) and a test of associative memory. Results: Pitta-Kapha is the most represented in the population. Results increase between the two times with decreasing severity of the cognitive and holistic status but not on the physical health. Memory complaints are weak or absent for the cognitive and memory. Regression models allow us to verify the predictions about health perception and associative memory. Conclusion: Cognitive stimulation is effective and ayurvedic categories offer a relevant frame for the understanding of the individual variants of the cognitive functioning in the healthy elderly.
\end{abstract}

Keywords: ayurvedic categories, cognitive stimulation, brain training, cognitive functions, health perception, complaint of memory, associative memory

\section{Introduction}

Ayurvedic medicine has been studied mainly for the benefits of plants and is the subject of ethno botanical survey (Adams, Gmunder, \& Hamburger, 2007). Many herbs such as brahmi, shatavari, and polygonum multiflorum are effective in treating cognitive impairment (Roodenrys, Booth, Bulzomi, Phipps, Micallef, \& Smoker, 2002; Ojha, Sahu, Muruganandam, Singh, \& Krishnamurthy, 2010; Liu, Durairajan, Lu, Koo, \& Li, 2011) and anxiety (Roodenrys et al., 2002). Indeed, these plants are potential cognitive enhancer and neuro protective against Alzheimer's disease (Ojha et al., 2010; Liu et al., 2011; Uabundit, Wattanathorn, Mucimapura, \& Ingkaninan, 2010). The lycoris radiata is particularly effective for the treatment of mild to moderate Alzheimer's disease (Howes \& Houghton, 2003). Also, relaxation improves the performance of long-term memory (Nava, Landau, Brody, Linder, \& Schächinger, 2004). Finally, meditation has a beneficial effect to treat and possibly prevent brain aging (Lonsdorf, Arenander, \& Shah, 2005).

Cognition is the set of mechanisms by which the organism acquires processes, maintains, and operates

\footnotetext{
*Acknowledgements: Special thanks go to E. Regent, director of the Public Hospital of Capesterre-Belle-Eau, Rotary Club of Guadeloupe, University of the Antilles and Guyane, for their invaluable contribution to this study.

Yenkamala Mina Ananda, Neuropsychologist and Ayurvedic Practitioner, M.D. of Psychology and B.D. of Ayurveda. Ayurvedic Institute of Guadeloupe. Research fields: Health psychology, Neuropsychology and Yogic Psychology (from Ayurveda).E-mail: yenkamala.mina@gmail.com.
} 
information. The mechanisms include perception, learning, memory, intelligence, and language. These cognitive functions, which are implanted in the brain, are formulated in the form of theoretical models of neuropsychology.

The animal models show the effect of training sessions on the acquisition and long-term memory in dogs (Demant, Ladewig, Balsby, \& Dabelsteen, 2011) and the effect of training on working memory in mice (Mohapel, Mundt-Petersen, Brundin, \& Frielingsdorf, 2006).

So, cognitive stimulation is beneficial for people with subjective complaints of memory (DeVreese, Belloi, Iacono, Finelli, \& Neri, 1998; Valentijn et al., 2005; Kuo, 2010; Rozenfeld Olchik, Farina, Maineri Steibel, \& Vargas, 2009). Several dimensions are taken into account as subjective and objective memory, life satisfaction, quality of life, and social support (Kuo, 2010).

Moreover, the use of strategies can explain the sustainable benefits of training (Cavallini, Pagnin, \& Vecchi, 2003; Bottiroli, Cavallini, \& Vecchi, 2008; O’Hara, Brooks, Friedman, \& Schröder, 2007). We have to consider the role of metacognitive attitudes of the elderly during training sessions on memory (Cavallini et al., 2003; Bottiroli et al., 2008). To add, training sessions positively influence cognitive abilities of working memory in young adults (Carretti, Borella, Zavagnin, \& DeBeni, 2011; Lee, Lu, \& Ko, 2007).

Demented people received neuropsychological intervention with computerized rehabilitation in order to stimulate visual and verbal memory and, verbal and spatial strategies and cognitive plasticity (Calero \& Navarro, 2007; Klingberg, 2010). Thus, cognitive training with 12 sessions improves memory performance of people with mild dementia (Panza, Solfrizzi, Mastroianni, Nard, Cicliola, \& Capurso, 1996).

By use of the video game Brain Age Nintendo ${ }^{\circledR}$ with older people, no clinical improvement was observed in subjects diagnosed with mild cognitive impairment, although some improvements in psychomotor processing speed were recorded (Hsiung, Kupferschmidt, Naus, Feldman, \& Jacova, 2009). The National Expertise Center in cognitive stimulation explains the invalid results by the lack of validity and specificity of brain training exercises from Nintendo ${ }^{\circledR}$.

Cognitive intervention is efficient for the treatment of depression in the elderly (Ekkers, Korrelboom, Huijbrechts, Smits, Cuijpers, \& Van der Gaag, 2011; Le Quellec, Fontaine, \& Réveillère, 2005) and in the adults (Naismith, Redoblado-Hodge, Lewis, Scott, \& Hickie, 2010), for the treatment of addiction (Bickel, Yi, Landes, Hill, \& Baxter, 2011), for the treatment of epilepsy with significant gains on anterograde and prospective memory (Radford, Lah, Thayer, \& Miller, 2011); it is efficient for the treatment of schizophrenia particularly in relation to autobiographical memory (Ricarte, Hernández-Viadel, Latorre, \& Rosa, 2011) and for the treatment of dyslexia with an improvement of the storage capacity of verbal and visual-spatial in working memory, and decoding, reading speed, and comprehension (Shiran \& Breznitz, 2011).

The objective of the present study was to determine the effectiveness of cognitive stimulation and to estimate the influence of the three ayurvedic constitutional categories on the effectiveness of cognitive stimulation over a period of three months. Based on the transactional model of health psychology, the general hypothesis tested here is that some biopsychosocial determiners have an impact on the effectiveness of cognitive stimulation and greatly influence memory and perception of their health.

\section{Methods}

\section{Participants}

The prevention of brain aging is proposed to retired people who were recruited from the University 
Antilles and Guyane. The training called Neuropeps ${ }^{\circledR}$ was designed by Jocelyne De Rotrou. The 12 sessions are conducted once a week and during two hours, from January to April 2012. The members of the Rotary Club of Guadeloupe participated as a controlled group. All participants received an information note explaining progress of the study. Thus, we guaranteed anonymity and confidentiality of their responses. They gave informed consent.

\section{Diagnostic Procedure}

Diagnosis of health was established according to MIS (the memory impairement screen) (DeRotrou et al., 2007). The procedure consisted in delayed free recall of a serie of four words, as a healthy memory corresponding to a score upper 6/8 (Yassuda et al., 2006) and age over 50 years.

The subjects should read aloud, and then denominate four words from their semantic category. Then, the words are hidden and a counting task from 1 to 20, then 20 to 1 is performed. Afterwards, they have to recall the four words. In case of failure to free recall, a cued recall from the semantic category is possible. The score ranges from 0 to 8 , with two points per free word recalled and one point for a cued recall.

Four words (leek, plane tree, whiting, and dahlia) have been adapted to the French population. The second step was a delayed recall MIS-D of the four words, about ten minutes after the first recall of MIS in the same procedure and free recall and cued, and the same rating from 0 to 8 . MIS targets mainly episodic memory that is extremely vulnerable during the early stages of Alzheimer's disease. The addition of a further step in a simple ten-minute delayed recall entitled MIS-D is particularly recommended for patients who complain about memory problems and even if they have a normal MIS ( 8 to 6 ). The MIS, with a threshold value to 6 , is a valid tool for tracking memory disorders mild to moderate and the MIS-D is a relevant complement to earlier detection of mild disorders.

We exclude individuals with a psychiatric history and disabling conditions in order to retain only healthy population.

\section{Neuropsychological Assessment}

The assessment involves two times:

During the pre-test (the first session for the group benefiting from the training), both groups completed a health questionnaire, a questionnaire about ayurvedic constitution (Smith, 2002), a self-assessment of health perception (DeVreese et al., 1998; Valentijn et al., 2005) and test of associative memory.

The post-test takes place three months later (last session for the group benefiting from the training). Participants will be tested again for their health perception and associative memory.

\section{Instrument}

The antecedents. Age, gender and marital status are collected during the first time of the study (Roodenrys et al., 2002; Kuo, 2010; Ekkers et al., 2011; Naismith et al., 2010).

The sociocultural level is assessed by a quotation used in clinical practice (Yassuda et al., 2006):

(1) illiterate;

(2) can read, write, and count;

(3) end of primary school leaving;

(4) certificate level of undergraduate studies (in total, from the first grade, nine years of school), or for manual jobs without specialization; 
(5) level graduating class (end of upper secondary education, 11 or 12 years of school), or for manual jobs, artisan, or laborer level with technical or management responsibilities;

(6) Bachelor level or highly qualified manual jobs with prolonged courses;

(7) university degree level.

The questionnaire of Prakriti (Smith, 2002) consists in 38 items. The participants choose among the three biological humors called Vata (V), Pitta (P) or Kapha (K), the one that best fits their situation. Once the questionnaire is completed, the total of each mood results in one of the seven constitutional categories. In clinical practice, the three double-categories are the most common: VP, VK, PV, PK, KV, and KP.

The mediators. Memory is assessed using a subjective scale of 0 to 20 listed as follows: $0=$ "My memory is a spendthrift"; 20 = "I have a memory like an elephant".

Perception of health is related to cognitive, mental, and quality of life which are evaluated by using a subjective scale 0 to 20 .

The questionnaire about complaint of memory (DeVreese et al., 1998; Valentijn et al., 2005) described "memory lapses" experienced by everyone in daily life. It includes eleven items on a scale of five-point: (1) "Never"; (2) "Rarely"; (3) "Sometimes"; (4) "Often"; and (5) "Always".

The criteria. Associative memory is assessed by a score on 15 (De Rotrou, 2008):

First, the participants have to remember 15 pairs of pictures (taken from Microsoft office online site). Then, there is a delayed recall by providing one of the two pictures that are associated.

\section{Procedure}

The scale was administered by a trained psychologist, and was completed face to face with the students and the Rotarians' consent.

The investigator was blind as the participants fill the scales by themselves.

\section{Statistical Analysis}

First, general characteristics and neuropsychological test of the 28 healthy people were compared using means and $t$-test for paired samples.

Second, general characteristics and neuropsychological tests of the 28 healthy people were compared using means and linear regression analysis where the antecedents and mediators are predictors and criteria are the variables to explain. All analyses were done using SPSS software (SPSS 17.0).

\section{Results}

A total of 20 subjects were included, 16 healthy elderly and 12 healthy controls. Among the subjects, there were 19 women and nine men; four were less than 60 years old, 16 were 60-69, and eight were 70 years old and older. Half of the subjects completed a university degree. Three were Kapha-Pitta (KP) category, one was Kapha-Vata (KV), 13 were Pitta-Kapha (PK), six Pitta-Vata (PV) and five were Vata-Pitta (VP). Figure 1 presents distribution of ayurvedic constitutions. There was no significant difference in age, gender, education and ayurvedic constitution between the two groups.

Means comparisons of participants are shown in Table 1. As expected, the results to scales increase between the two times with decreasing severity of the cognitive and holistic status but not on the physical health. 


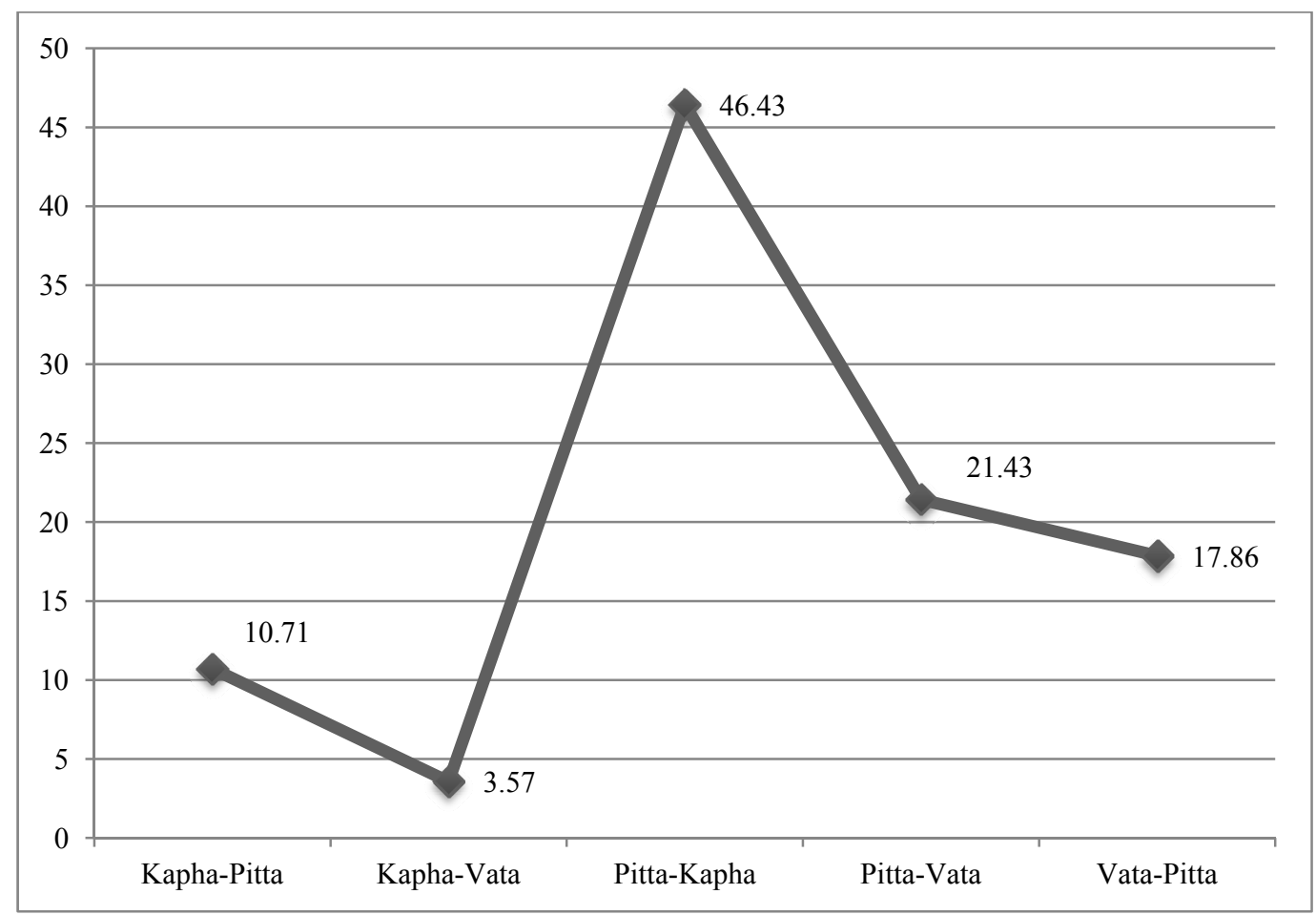

Figure 1. Distribution of the ayurvedic constitutions. Results are percentages.

Table 1

Neuropsychological Performances and Health Perception of the Healthy Subjects

\begin{tabular}{lllll}
\hline & Mean & $N$ & Standard-deviation & $p$-value \\
\hline Subjective memory T1 & 13.54 & 28 & 4.221 & 0.000 \\
Subjective memory T2 & 13.57 & 28 & 3.024 & \\
Perceived physical health T1 & 14.36 & 28 & 2.996 & 0.093 \\
Perceived physical health T2 & 14.11 & 28 & 3.095 & \\
Perceived mental health T1 & 14.89 & 28 & 4.149 & 0.000 \\
Perceived mental health T2 & 15.96 & 28 & 3.203 & 0.009 \\
Perceived well-being T1 & 15.64 & 28 & 3.094 & \\
Perceived well-being T2 & 15.68 & 28 & 2.653 & 0.000 \\
Associative memory T1 & 5.67 & 24 & 3.852 & \\
Associative memory T2 & 8.29 & 24 & 5.229 & \\
\hline
\end{tabular}

Notes. $p$-value assessed by $t$-test analysis of variance. Results are means and standard deviation.

Table 2 shows the levels of memory complaint among the subjects. Overall, memory complaints are weak or absent for the cognitive and memory. However, there is a complaint for the memory of names and for the memory of numbers.

We tested several models to verify the predictions. In the first regression (see model 1 in Table 3 ), higher socio-cultural levels are related to higher associative memory scores three months later. The second regression (see model 2 in Table 3) indicates that higher sociocultural levels are related to higher physical health scores after three months. Thus, evolution of overall health (cognitive, physical, mental, and quality of life) and evolution of associative memory performance do not depend on the medical factor. 
Table 2

Levels of Memory Complaint Among the Healthy Subjects

\begin{tabular}{|l|l|}
\hline $\begin{array}{l}\text { No complaint } \\
(<50)\end{array}$ & $\begin{array}{l}\text { Topographic memory and spatial orientation (43\%); semantic memory }(64 \%) ; \\
\text { autobiographical memory }(53 \%)\end{array}$ \\
\hline $\begin{array}{l}\text { Low complaint } \\
(40-50)\end{array}$ & $\begin{array}{l}\text { Attention and working memory }(46 \%) ; \text { memory of location of objects }(36 \%) ; \\
\text { memory of common names }(36 \%) ; \text { memory of numbers }(29 \%) ; \text { memory of source }(46) ; \\
\text { prospective memory }(36)\end{array}$ \\
\hline $\begin{array}{l}\text { Major complaint } \\
(>40)\end{array}$ & Memory of names (32\%); memory of numbers $(29 \%)$ \\
\hline
\end{tabular}

Note. Results are percentages with numbers in parentheses.

Table 3

Predictive Role of Socio-Biographical Factors on Adjustment Criteria for Cognitive Stimulation Efficiency in Healthy Elderly

\begin{tabular}{llllll}
\hline & Degree of liberty & $F$ & $R^{2}$ & $\beta$-standardized & $p$-value \\
\hline Model 1 & 9 & 6.666 & 0.811 & & 0.001 \\
Sociocultural level & & & & 0.385 & 0.40 \\
Model 2 & 9 & 2.816 & 0.585 & & 0.029 \\
Sociocultural level & & & & 0.507 & 0.025 \\
\hline
\end{tabular}

Notes. $p$-values assessed by linear regression analysis. Results are the significance of models.

The third regression (see model 1 in Table 4) shows very significantly that Pitta-Kapha (PK) constitutions are more interested to inform about daily news than the Vata constitutions. Thus, sociobiographical factors do not predict the overall perceived health and lack of semantic memory complaint.

Table 4

Predictive Role of Socio-Biographical Factors on Mediators for Cognitive Stimulation Efficiency in Healthy Elderly

\begin{tabular}{llllll}
\hline & Degree of liberty & $F$ & $R^{2}$ & $\beta$-standardized & $p$-value \\
\hline Model 1 & 9 & 4.860 & 0.708 & & 0.002 \\
Prakriti & & & -7.652 & 0.004 \\
Main prakriti & & & -7.487 & 0.004 \\
Secondary prakriti & & & -2.252 & 0.007 \\
\hline
\end{tabular}

Notes. $p$-values assessed by linear regression analysis. Results are the significance of models.

The fourth regression (see model 1 in Table 5) indicates that the lack of topographic memory complaint and the lack of spatial orientation predict good mental health three months later.

In the fifth regression (see model 2 in Table 5), quality of life, lack of working memory complaint, lack of attention disturbance, and high memory of names complaint and high prospective memory complaint predict a better quality of life three months later.

Finally (see model 3 in Table 5), good perceived physical health and higher memory for the location of objects complaints predict lower memory of common names complaint. Also, they have a better evolution of their subjective memory between the two times. 
Table 5

Predictive Role of the Mediators on Criteria for Cognitive Stimulation Effectiveness in Healthy Elderly

\begin{tabular}{|c|c|c|c|c|c|}
\hline & Degree of liberty & $F$ & $R^{2}$ & $\beta$-standardized & $p$-value \\
\hline Model 1 & 15 & 3.854 & 0.828 & & 0.012 \\
\hline $\begin{array}{l}\text { Topographic memory and spatial } \\
\text { orientation complaint }\end{array}$ & & & & -0.541 & 0.026 \\
\hline Model 2 & 15 & 3.594 & 0.818 & & 0.016 \\
\hline Quality of life at T1 & & & & 0.707 & 0.020 \\
\hline Working memory and attention complaint & & & & -0.458 & 0.029 \\
\hline Memory of names complaint & & & & -0.604 & 0.038 \\
\hline Prospective memory complaint & & & & 0.724 & 0.010 \\
\hline Model 3 & 15 & 2.853 & 0.781 & & 0.037 \\
\hline Perceived physical health & & & & 0.807 & 0.020 \\
\hline Memory of location of objects complaint & & & & 0.499 & 0.039 \\
\hline Common names memory complaint & & & & -0.608 & \\
\hline
\end{tabular}

Notes. $p$-values assessed by linear regression analysis. Results are the significance of models.

\section{Discussion}

Healthy people have good perception of their health whether cognitive, physical, mental, and also their quality of life suggesting that all dimensions are closely related as shown in ayurvedic medicine.

Subjects with a high level of education have better associative memory and better perception of physical health compared to lower levels, which is often linked to a high socio-economic status giving easy access to prevention and care. Thus, we have confirmed the beneficial effect of cognitive stimulation on a specific type of memory in elderly with high sociocultural level (Yassuda et al., 2006).

The use of the constitutions of the ayurvedic system is an original and innovative work in its applications to neuropsychological functioning of the individual. Studies generally focus onherbal ayurvedic knowing that these categories are used for diagnosis from which to choose plants based on disease and according to the constitution of birth called Prakriti (Smith, 2002).

As Pitta-Kapha category predicts a very significant lack of semantic memory complaints, PK presents a clear memory and a bright mental nature corresponding to Pitta, but also robust storage for Kapha (Smith, 2002). These characteristics are compatible with an interest or daily news and are a kind of cerebral protection for semantic memory that is the memory of knowledge about the world (De Rotrou, 2008).

For the group receiving the program, each of the 12 sessions began with a review of daily news. This has certainly contributed to reinforcing semantic memory capacities, and thus to removing a memory complaint.

Finally, a lack of topographic memory and spatial orientation complaint predict better mental health three months later.

The aged people have a good perception of their quality of life, a lack of working memory and attention complaints, a lack of memory of names complaint, and a major prospective memory complaint that are related to a good quality of life three months later. As Kuo's team (Kuo, 2010), we showed the impact of cognitive stimulation on various dimensions underlying mental health in healthy elderly. However, it is surprising that a prospective memory complaint (or memory of what one plans to do) predicts a good quality of life over time.

Our population complains little about prospective memory that is memory of the projects maybe because they do fewer projects at time of retirement. 
A good perception of physical health, a major memory complaint of the locations of the objects and a lack memory of names complaints predict a good evolution of subjective memory. When you are older, they consider that is normal to stop making project and to forget the location of objects.

So, the cognitive intervention Neuropeps ${ }^{\circledR}$ is effective on memory performance in persons with subjective and objective memory complaints (DeVreese et al., 1998; Valentijn et al., 2005; Kuo, 2010; Rozenfeld Olchik et al., 2009).

Through the results observed previously, we confirmed our general hypothesis: That certain antecedent or mediating variables impact on the effectiveness of cognitive stimulation over time.

\section{Limitations of the Study}

In this prospective and longitudinal study with a control group, we have evaluated the effectiveness of cognitive stimulation using validated self-administered questionnaires and scales of perceived health. The volunteers' people were recruited to participate to the study. Therefore, the population was not influenced by the biases of the researcher.

It would be necessary to continue this study over a longer period to have a larger sample and thus confirm these results and, to compare the factors with ayurvedic constitutions.

\section{Strengths of the Study}

The culmination of this original work that blends ayurvedic system, neuropsychology and health psychology could be the development of cognitive stimulation based on ayurvedic constitutions that is to say a program about health prevention in order to educate people on how to live long and healthy, more precisely with diet, lifestyle, psychotherapy, and phytotherapy.

\section{Conclusion}

Through the energetic concept of biological forces called doshas, we have established relationships with the cognitive, somatic and emotional factors of the individuals: Vata as the principle of movement; Pitta, the principle of transformation; Kapha for cohesion.

Older people encountered were trained in various cognitive strategies during sessions of cognitive and psychosocial stimulation; these techniques are already used for a variety of diseases such as epilepsy, schizophrenia and depression but also for healthy people. The main purpose of these programs is to give the person an active role to prevent brain aging and to prevent undesirable consequences and complications.

Holistic approaches such as Ayurveda, health psychology and clinical neuropsychology give opportunities for cooperation between traditional and allopathic practitioners to improve the treatment of patients with brain injuries.

\section{References}

Adams, M., Gmunder, F., \& Hamburger, M. (2007). Plants traditionally used in age related brain disorders: A survey of ethno botanical literature. Journal of Ethno Pharmacology, 113, 363-381.

Bickel, W. K., Yi, R., Landes, R. D., Hill, P. F., \& Baxter, C. (2011). Remember the future: Working memory training decreases delay discounting among stimulant addicts. Biol. Psychiatry, 69, 260-265.

Bottiroli, S., Cavallini, E., \& Vecchi, T. (2008). Long-term effects of memory training in the elderly: A longitudinal study. Archives of Gerontology and Geriatrics, 47, 277-289. 
Calero, M. D., \& Navarro, E. (2007). Cognitive plasticity as a modulating variable on the effects of memory training in elderly persons. Archives of Clinical Neuropsychology, 22, 63-72.

Carretti, B., Borella, E., Zavagnin, M., \& DeBeni, R. (2011). Impact of metacognition and motivation on the efficacy of strategic memory training in older adults: Analysis of specific transfer and maintenance effects. Archives of Gerontology and Geriatrics, 52, 192-197.

Cavallini, E., Pagnin, A., \& Vecchi, T. (2003). Aging and everyday memory: The beneficial effect of memory training. Arch. Gerontol. Geriatr., 37, 241-257.

Demant, H., Ladewig, J., Balsby, T. J. S., \& Dabelsteen, T. (2011). The effects of frequency and duration of training sessions on acquisition and long-term memory in dogs. Applied Animal Behaviour, 133, 28-234.

De Rotrou, J. (2008). NEUROPEPS®, programme de prévention pourune bonnesanté cognitive.

De Rotrou, J., Battal-Merlet, L., Wenish, E., Chausson, C., Bizet, E., Dray, F., Lenoir, H., Rigaud, A. S., \& Hanon, O. (2007). Relevance of 10-min delayed recall in dementia screening. European Journal of Neurology, 14, 144-149.

De Vreese, L. P., Belloi, L., Iacono, S., Finelli, C., \& Neri, M. (1998). Memory training programs inmemory complainers: Efficacy on objective and subjective memory functioning. Arch. Gerontol. Geriatr.,suppl. 6, 141-154.

Ekkers, W., Korrelboom, K., Huijbrechts, I., Smits, N., Cuijpers, P., \& Van der Gaag, M. (2011). Competitive memory training for treating depression and rumination in depressed olderadults: A randomized controlled trial. Behaviour Research and Therapy, 49, 588-596.

Hsiung, G. Y. R., Kupferschmidt, A., Naus, K., Feldman, H. H., \& Jacova, C. (2009). Cognitive and clinical outcomes in a pilot study using a hand held computer game for cognitive training of patients with mild cognitive impairment (MCI). Poster Presentations, P3, 411.

Howes, M. J. R., \& Houghton, P. J. (2003). Plants used in Chinese and Indian traditional medicine for improvement of memory and cognitive function. Pharmacology, Biochemistry and Behavior, 75, 513-527.

Klingberg, T. (2010). Training and plasticity of working memory. Trendsin Cognitive Sciences, 14, 317-324.

Kuo,T. (2010). Evaluation of a memory training program for community elders in Taiwan. Poster Presentations, P1, 177-178.

Lee, Y., Lu, M., \& Ko, H. (2007). Effects of skill training on working memory capacity. Learning and Instruction, 17, 336-344.

Le Quellec, S., Fontaine, R., \& Réveillère, C. (2005). Évaluation de l'efficacité d'un entraînement mnésique chez des personnes très âgées dépressives institutional isées. Psychologie Française, 50, 437-450.

Liu, L. F., Durairajan, S. S. K., Lu, J. H., Koo, I., \& Li, M. (2011). Invitro screening onamyloid precursor protein modulation of plants used in a yurvedic and traditional Chinese medicine for memory improvement. Journal of Ethnopharmacology, 1-7.

Lonsdorf, N., Arenander, A., \& Shah, Y. (2005). Neurological understanding of ayurvedic medicine and its application to dementia prevention. Nonpharmaco Logical and Lifestyle Interventions, 1, suppl.1.

Mohapel, P., Mundt-Petersen, K., Brundin, P., \& Frielingsdorf, H. (2006). Working memory training decrease ship pocampal neurogenesis. Neuroscience, 142, 609-613.

Naismith, S. L., Redoblado-Hodge, M. A., Lewis, S. J. G., Scott, E. M., \& Hickie, I. B. (2010). Cognitive training in affective disorders improves memory: A preliminary study using the NEAR approach. Journal of Affective Disorders, 121, 258-262.

Nava, E., Landau, D., Brody, S., Linder, L., \& Schächinger, H. (2004). Mental relaxation improves long-term incidental visual memory. Neurobiology of Learning and Memory, 81, 167-171.

O'Hara, R., Brooks, J. O., Friedman, L., \& Schröder, C. M. (2007). Long-term effects of mnemonic training in community dwelling older adults. Journal of Psychiatric Research, 41, 585-590.

Ojha, R., Sahu, A. N., Muruganandam, A. V., Singh, G. K., \& Krishnamurthy, S. (2010). Asparagus racemosus enhances memory and protects against amnesia inrodent models. Brain and Cognition, 74, 1-9.

Panza, F., Solfrizzi, V., Mastroianni, F., Nard, G. A., Cicliola, F., \& Capurso, A. (1996). A rehabilitation program for mild memory impairments. Arch. Gerontol. Geriatr., Suppl.5, 51-55.

Radford, K., Lah, S., Thayer, Z., \& Miller, L. A. (2011). Effective group-based memory training for patients with epilepsy. Epilepsy and Behavior, 22, 272-278.

Ricarte, J. J., Hernández-Viadel, T., Latorre, J. M., \& Rosa, L. (2011). Effects of event-specific memory training on autobiographical memory retrieval and depressive symptoms in schizophrenic patients. Journal of Behaviour Therapy and Experimental Psychiatry, 3, 1-9.

Rozenfeld Olchik, M., Farina, J., Maineri Steibel, N., \& Vargas, R. (2009). The profile of patients engaged in cognitive training at a memory clinic. Poster Presentations, P2, 333. 
Roodenrys, S., Booth, D., Bulzomi, S., Phipps, A., Micallef, C., \& Smoker, J. (2002). Chronic effects of brahmi (bacopa monnieri) on human memory. Neuropsycho Pharmacology, 27, 2.

Shiran, A., \& Breznitz, Z. (2011). The effects of cognitive training on recall range and speed of information proessing in the working memory of dyslexic and skilled readers. Journal of Neurolinguistics, 24, 524-537.

Smith, A. (2002). La psychologiede la transformationen yoga. Monoblet: Editions Turiya.

Uabundit, N., Wattanathorn, J., Mucimapura, S., \& Ingkaninan, K. (2010). Cognitive enhancement and neuroprotective effects of bacopamonnieri in Alzheimer's disease model. Journal of Ethno Pharmacology, 127, 26-31.

Valentijn, S. A. M., Van Hooren, S. A. H., Bosma, H., Touw, D. M., Jolles, J., Van Boxtel, M. P. J., \& Ponds, R. W. H. M. (2005). The effect of two types of memory training on subjective and objective memory performance in healthy individuals aged 55 years and older: Arandomized controlled trial. Patient Education and Counselling, 57, 106-114.

Yassuda, M. S., Viola, L., Pereira, F., Flaks, M. K., Cid, C. G., Carolina, A., \& Regina, B. (2006). Memory training for highly educated control participants with memory complaints: Benefits and mechanisms. Poster Presentations, P4, 572-573.

\section{Appendix 1}

Information for the elderly participating in the memory training program.

Dear Sir or Madam,

In the context of the prevention of brain aging, we would like to better understand the performance of your memory.

So, your participation will be particularly valuable in a study which the aim is to estimate the benefits of cognitive stimulation and the influence of your lifestyle on the effectiveness of the memory training program.

The first group will participate to the cognitive stimulation program in 12 sessions, and the controlled group won't have stimulation memory.

This study involves two times: The first time is an interview lasting approximately duration of 30 minutes; the second time will be held by interwiew and also by phone, about three months after the first meeting.

During these interviews, the psychologist will propose you to complete various questionnaires, to better understand the relation between the types of memory and the ayurvedic constitutions.

This assessment shall not affect your participation to the memory training program at "University of the free time". You can feel free to stop participating if you want and without having to justify it.

We will ensure anonymity and privacy of your answers throughout your participation and they will be protected by medical confidentiality. We are aware that such participation may require efforts. So, thank you in advance for your help. 
Appendix 2

Relation between the different types of memory and the ayurvedic constitutions:

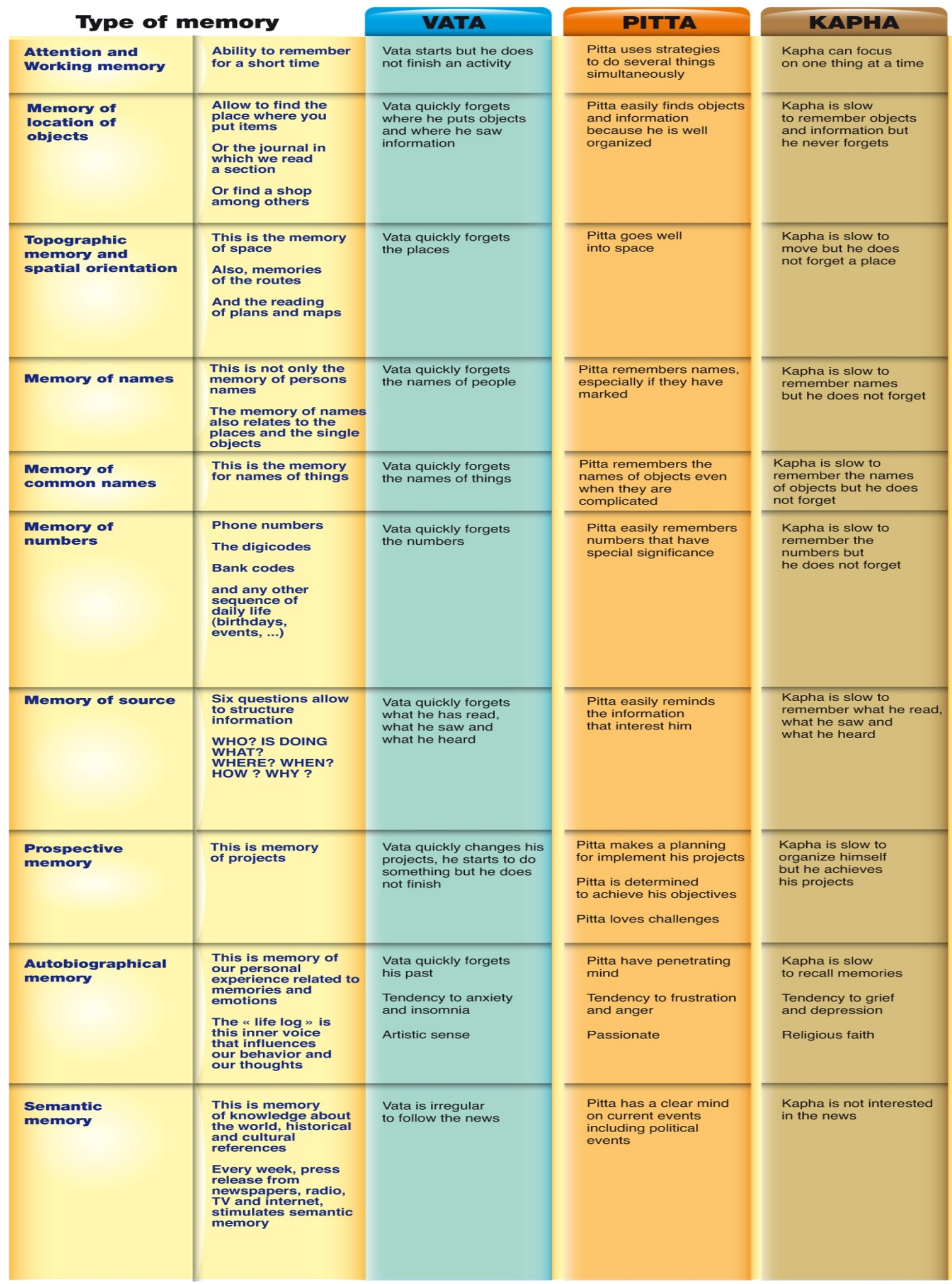

